\title{
Hubungan Supervisi Akademik Kepala Madrasah dengan Peningkatan Mutu Pembelajaran di Madrasah Tsanawiyah Jamiatul Huda Kabupaten Bekasi
}

\author{
Tatang Ibrahim \\ Fakultas Tarbiyah dan Keguruan Universitas Islam Negeri (UIN) Sunan Gunung Djati Bandung \\ E-mail: tatangibra15@gmail.com \\ Siti Robiah \\ Jurusan Manajemen Pendidikan Islam Fakultas Tarbiyah dan Keguruan \\ Universitas Islam Negeri (UIN) Sunan Gunung Djati Bandung
}

\begin{abstract}
The essence of education is a learning process. There is no quality education without quality learning. Changes in the system of management, both from the point of view of educators and educational personnel, must have clear supervision. Therefore, in order to improve the quality of education in madrasah, the government, in this case the Ministry of National Education, is developing various programs which are expected to improve the quality of learning, especially through supervision activities. This study aims to determine whether there is a positive and significant relationship between the academic supervision of the head of madrasah and the improvement of the quality of learning at Madrasah Tsanawiyah Jamiatul Huda Bekasi district. This research is based on the idea that one of the ways to improve the quality of education is by increasing the quality of learning. In this case the learning process is an important component in determining the quality of education. besides teachers and students who are in the implementation of the learning process. The activities of the principal of madrasah in supervising, guiding, fostering teachers in the learning process use academic supervision. For this reason, the research was conducted to determine whether there was a relationship between the academic supervision of the head of the madrasah and the improvement of the quality of learning at Madrasah Tsanawiyah Jamiatul Huda, Bekasi district. The approach used in this study is a quantitative approach, correlational type and uses a simple linear regression method. The population is all teacher councils at Madrasah Tsanawiyah Jamiatul Huda Bekasi Regency and as many as 28 people. Research data using the SPSS 26 for windows program. The results of this study indicate that the academic supervision of the head of madrasah has a positive and significant relationship with the improvement of the quality of learning at Madrasah Tsanawiyah Jamiatul Huda Bekasi district. Based on the results of the research, the following
\end{abstract}


suggestions can be made: (1) Madrasah supervisors and madrasah principals are expected to supervise not only matters of an administrative nature, but prioritizes supervision in the academic field, so as to improve the innovative performance of teachers who In the end, improve the quality of education, (2) maximize classroom observations or class assessments, so that the head of madrasah is aware of teacher teaching developments and teacher constraints and is able to provide solutions in improving the learning process.

Keywords: Academic Supervision, Quality of Learning

\section{PENDAHULUAN}

Supervisi akademik merupakan suatu suatu pelaksanaan dalam membantu guru oleh kepala madrasah untuk meningkatkan kemampuan profesionalisme guru paling utama dalam proses pembelajaran demi mencapai tujuan pembelajaran yang diharapkan. Esensi dari supervisi akademik ini sama sekali bukan menilai kinerja guru dalam mengelola pembelajaran, melainkan suatu bentuk kerjasama dan membantu guru untuk mengembangkan skill/kemam-puannya.

Melaksanakan supervisi akademik perlu membutuhkan perencanaan yang matang dan serius sehingga dapat menerapkan prinsip-prinsip supervisi akademik dengan baik, karena kemampuan ini penting bagi seorang kepala madrasah. Pelaksanaan supervisi akademik, perlu ditentukan model, teknik, pendekatan, dan metode yang tepat dengan kondisi dan potensi madrasah, tentukan tindak lanjut dari hasil pengawasan, yang semuanya perlu direncanakan sehingga tujuan pembinaan, metode dan kegiatan sehingga supervisi akademik berjalan dengan baik dan terstruktur.(Mintadji, 2015)

Berhasil tidaknya sekolah dalam mencapai tujuan serta mewujudkan visi dan misinya terletak pada bagaimana manajemen dan kepemimpinan kepala madrasah, khususnya dalam menggerakkan dan memberdayakan berbagai komponen yang ada di sekolah. Dalam prosesnya, yaitu interaksi berkualitas yang dinamis antar kepala madrasah, guru, tenaga administrasi, dan peserta didik memainkan peran yang sangat penting, terutama dalam penyesuaian berbagai aktivitas di sekolah dengan tuntutan globalisasi saat ini, perubahan masyarakat, serta kondisi dan lingkungannya.

Untuk membantu kinerja guru agar setiap program dapat berjalan dengan efektif dan efisien serta sesuai dengan perencanaan maka diperlukan pengawasan atau supervise oleh kepala madrasah. Supervisi merupakan tugas pekerjaan pokok dalam administrasi pendidikan dari kepala madrasah terhadap pegawai- pegawai sekolahnya. Supervisi akademik yaitu proses kepemimpinan kepala madrasah dalam 


\section{BESTARI}

Vol. 17, No. 2, 2020

p-ISSN 1907-1337; e-ISSN 2807-6532

pendidikan yang bertujuan untuk membantu mengembangkan professio-nal guru khususnya dalam mengajar sesuai observasi dan analisis data secara teliti dan obyektif sebagai pegangan untuk perubahan tingkah laku mengajar tersebut. (Gunawan, 2011)

Mutu pembelajaran merupakan suatu hal pokok yang harus diperbaiki atau dibenahi dalam peningkatan mutu pendidikan. Pembelajaran pada dasarnya merupakan suatu kegiatan akademik yang dilakukan dengan berupa interaksi komunikasi antara pendidik dan peserta didik dalam proses ini merupakan sebuah tindakan professional yang terpacu pada kaidah-kaidah ilmiah. Dalam hal ini guru perlu mengaktifkan proses pembelajaran dengan menggunakan berbacai metode belajar.

Pembelajaran yang dilakukan oleh guru sangat menentukan arah mutu pembelajaran yang dapat diperoleh peserta didik. Indicator mutu pembelajaran itu sendiri yaitu kesesuaian, pembelajaran yang bermutu juga mempunyai daya Tarik yang kuat, efektivitas, efisiensim, dan produktivitas. (Abdurrahman, 2012)

Orang yang berada di jajaran utama dalam menentukan mutu pendidikan adalah guru. Karena guru adalah orang yang setiap hari selalu berhadapan dengan peserta didik. Maka dari itu diperlukan guru yang mempunyai kualitas.

Adanya supervise akademik diharapkan mampu mengembangkan kualitas guru serta mampu membuat situasi belajar mengajar yang lebih baik dan bermutu untuk membantu dalam pencapaian tujuan pendidikan madrasah, membantu guru dalam menyelesaikan permasalahan dalam pembelajaran, misalnya membimbing guru yang belum paham menggunakan media pembelajaran yang modern, serta membantu guru dalam menilai perkembangan siswa.

Berdasarkan studi pendahuluan yang dilakukan peneliti pada bulan November 2019 kondisi pendidik di MTs Jamiatul Huda Kabupaten Bekasi diperoleh hasil wawancara bersama guru bagian kurikulum, bahwa sebagian besar tenaga pendidik yang ada sudah linier secara administrative.

Perekrutan tenaga pendidik di MTs Jamiatul Huda Kabupaten Bekasi sudah terbilang cukup baik. Namun, ada sedikit beberapa masalah yang terkait dengan implementasi proses pembelajaran, dimana proses tersebut masih belum mencapai standar nasional.

Penyebab yang oleh berbagai faktor yang ada, diantaranya faktor penyajian materi yang belum mendapatkan fasilitas pendukung secara maksimal, contohnya ruang kelas yang tidak kedap suara sehingga masih terdengar suara-suara keributan dari luar kelas lain yang menyebabkan kurang efektifnya suatu proses pembelajaran.

Faktor selanjutnya terletak pada tenaga pendidik yang merujuk pada sebagian besar guru yang linier, hanya sebagian kecil guru yang dikatakan ideal dan memiliki kualitas tinggi. Selebihnya masih 
dinyatakan kurang atau kualitasnya rendah, karena hampir semua guru bertugas dibeberapa sekolah luar yang tidak hanya terfokus di MTs Jamiatul Huda Kabupaten Bekasi, dan hanya sebagian kecil guru yang memilih untuk tetap fokus bertugas di MTs Jamiatul Huda Kabupaten Bekasi tersebut. Faktor terakhir adalah kurangnya komitmen para pendidik, yang masih memiliki anggapan tugas mereka hanya sebatas mengajar di dalam kelas.

Berdasarkan latar belakang permasalahan di atas, peneliti tertatrik untuk mengetahui lebih dalam tentang mutu pembelajaran guru yang ditinjaudari faktor yang mempengaruhinya, yaitu supervisi akademik kepala madrasah sehingga peneliti menetapkan judul Hubungan Supervisi Akademik Kepala Madrasah Dengan Peningkatan Mutu Pembelajaran di MTs Jamiatul Huda Kabupaten Bekasi.

\section{METODE}

Metode yang digunakan dalam penelitian ini adalah metode deskriptif dengan jenis studi korelasi. Penelitian dilaksanakan di Madrasah Tsanawiyah Jamiatul Huda Kabupaten Bekasi dengan waktu penelitian pada bulan November 2019.

Populasi pada penelitian ini adalah seluruh guru yang ada di Madrasah Tsanawiyah Jamiatul Huda Kabupaten Bekasi berjumlah 28 orang. Sampel pada penelitian ini mengunnakan metode NonProbability Sampling yang dipilih yaitu dengan sampling jenuh (sensus) yang diambil yaitu dengan jumlah sampel 28 responden dari jumlah keselurhan populasi.

Intrumen pengumpulan data menggunakan kuesioner melalui Google form dengan dua variabel yaitu: supervisi akademik kepala madrasah yang terdiri dari lima belas pertanyaan dengan jawaban berupa kata-kata seperti: (SS) sangat setuju, (S) setuju, (R) Ragu, (TS) tidak setuju, (STS) Sangat tidak setuju. Dengan hasil supervisi akademik kepala madrasah distribusi frekuensi sebesar 0.904 dengan kategori sangat tinggi. Kuesioner tentang pertanyaan peningkatan mutu pembelajaran dari dua belas pertanyaan dengan jawaban berupa kata-kata seperti: (SS) sangat setuju, (S) setuju, (R) Ragu, (TS) tidak setuju, (STS) Sangat tidak setuju. Dengan hasil peningkatan mutu pembelajaran distribusi frekuensi sebesar 0.867 dengan kategori sangat tinggi.

Pengumpulan data dilakukan sesuai jadwal yang diatur, setelah mendapat persetujuan dari pembimbing dan penguji proposal, dengan menggunakan instrumen kuesioner. Pada lokasi penelitian dilakukan setelah mendapatkan izin dari kepala madrasah di tempat penelitian. Kuesionerdiisi oleh seluruh guru dengan jumlah responden 28 orang dan sudah adanya persetujuan dari masing-masing responden.

Pengolahan data merupakan proses penataan data, karena data yang terkumpul merupakan suatu data kasar yang perlu diolah. Pengolahan data ini terdiri dari :Editing yaitu peneliti melakukan Editing 


\section{BESTARI}

Vol. 17, No. 2, 2020

p-ISSN 1907-1337; e-ISSN 2807-6532

dengan data yang diperoleh sudah terisi lengkap, tulisan telah jelas terbaca, dan tidak ada kebiasan dalam penafsiran data. Coding yaitu suatu proses penyusunan secara sistematis data mentah dari kuesioner dengan ketentuan yang ada, yakni dengan menggunakan Rating Scale ( $S S=5, S=4, R G=3, T S=2, S T S=1)$. Entry Data yaitu Setelah peneliti melakukan sebuah proses memasukan data ke dalam computer selanjutnya di lakukan analisis data dengan menggunakan software statistic. Cleaning Setelah peneliti melakukan sebuah proses memasukan data ke dalam computer selanjutnya di lakukan analisis data dengan menggunakan software statistic. Tabulating Setelah Peneliti melakukan memasukan data-data hasil penelitian ke dalam tabel sesuai kriteria.

Analisa data untuk melihat hubungan supervisi akademik kepala madrasah dengan peningkatan mutu pembelajaran di Madrasah Tsanawiyah Jamiatul Huda Kabupaten Bekasi. Dimana data analisis dengan menggunakan Uji Koefisien Determinasi R atau Square (r2) pada kemaknaan 57\% dengan bantuan program SPSS 26.

\section{HASIL PENELITIAN}

\section{Uji Normalitas}

Setelah melakukan penelitian, maka peneliti memperoleh sampel sebanyak 28 responden, dengan pengujian prasyarat analisis dilakukan dengan uji normalitas dan uji linieritas sebagai berikut:

Tabel 1. Uji Normalitas

One-Sample Kolmogorov-Smirnov Test

\begin{tabular}{|ll|r|r|}
\hline & & $\begin{array}{c}\text { Supervisi } \\
\text { Akademik } \\
\text { Kepala } \\
\text { Madrasah } \\
\text { (X) }\end{array}$ & $\begin{array}{c}\text { Peningkatan Mutu } \\
\text { Pembelajaran(Y) }\end{array}$ \\
\hline $\mathrm{N}$ & & 28 & 28 \\
Normal Parameters & & & \\
& Mean & 59.0000 & 46.1429 \\
Most Extreme & Std. Deviation & 6.73300 & 5.93617 \\
Differences & Absolute & .081 & .078 \\
Test Statistic & Positive & .081 & .059 \\
Asymp. Sig. (2-tailed) & & -.078 & -.078 \\
\hline
\end{tabular}

a. Test distribution is Normal.

b. Calculated from data.

c. Lilliefors Significance Correction.

d. This is a lower bound of the true significance.

Dari hasil tabel diatas dapat ditarik kesimpulan, bahwa data pada variabel supervisi akademik kepala madrasah (X), peningkatan mutu 
pembelajaran (Y) memiliki nilai signifikansinya 0,200, karena signifikansinya lebih dari 0,05 jadi data dinyatakan berdistribusi normal.

Tabel 2. Uji Linieritas

ANOVA Table

\begin{tabular}{|c|c|c|c|c|c|c|c|}
\hline & & & $\begin{array}{l}\text { Sum of } \\
\text { Squar es }\end{array}$ & $\mathrm{df}$ & $\begin{array}{l}\mathrm{Me} \\
\text { an Sq } \\
\text { uar e }\end{array}$ & $\mathrm{F}$ & Sig. \\
\hline \multirow{5}{*}{$\begin{array}{l}\text { Penmgkatan } \\
\text { Mutu } \\
\text { Pembelajaran(Y) } \\
\text { * Supervisi } \\
\text { Akademik Kepala } \\
\text { Madrasah (X) }\end{array}$} & \multirow[t]{3}{*}{$\begin{array}{l}\text { between } \\
\text { Groups }\end{array}$} & $\begin{array}{l}\text { (Compm } \\
\text { ed) }\end{array}$ & 703.095 & 17 & & 2.383 & .082 \\
\hline & & Linearity & 544.000 & 1 & 544.000 & 28.885 & .000 \\
\hline & & $\begin{array}{l}\text { Deviatio n } \\
\text { from } \\
\text { Linearity }\end{array}$ & 219.095 & 16 & 13.693 & .727 & .725 \\
\hline & \multicolumn{2}{|c|}{ Within Groups } & 188.333 & 10 & 18.833 & & \\
\hline & \multicolumn{2}{|l|}{ Total } & 951.429 & 27 & & & \\
\hline
\end{tabular}

Berdasarkan tabel di atas, hasil uji linieritas supervisi akademik kepala madrasah dengan peningkatan mutu pembelajaran diperoleh nilai $\mathrm{F}=0,727$ dengan tingkat signifikansi 0,725 . Tingkat signifikansi akan dibandingkan dengan 0,05 (karena menggunakan taraf signifikansi atau $\alpha=5 \%) .0,725>0,05$ maka Ho diterima artinya ada hubungan yang linier antar supervisi akademik dengan peningkatan mutu pembelajaran. Berdasarkan uji linieritas pada tabel diatas dapat disimpulkan bahwa hubungan antara variabel bebas dengan variabel terikat bersifat linier, hal ini dibuktikan dengan Phitung $>0,05$.

Untuk mencari persamaan regresinya dengan bantuan SPSS 26 didapat hasil sebagai berikut. 


\section{BESTARI}

Vol. 17, No. 2, 2020

p-ISSN 1907-1337; e-ISSN 2807-6532

Tabel 3. Uji Persamaan Regresi Coefficientsa

\begin{tabular}{|c|c|c|c|c|c|}
\hline \multirow[b]{2}{*}{ Model } & \multicolumn{2}{|c|}{$\begin{array}{l}\text { Unstandardi } \\
\text { zed Coefficients }\end{array}$} & $\begin{array}{c}\text { Standardi } \\
\text { zed Coefficie } \\
\text { nts }\end{array}$ & \multirow[b]{2}{*}{$\mathrm{t}$} & \multirow[b]{2}{*}{ Sig. } \\
\hline & B & $\begin{array}{l}\text { Std. } \\
\text { Erro r }\end{array}$ & Beta & & \\
\hline $\begin{array}{ll}1 & \text { (Constant) } \\
& \text { Supervisi }\end{array}$ & 6.81 & 6.71 & & $\begin{array}{r}1.0 \\
14\end{array}$ & $\begin{array}{r}.32 \\
0\end{array}$ \\
\hline Akademik Kepala & .667 & .113 & .756 & $\begin{array}{r}5.8 \\
92\end{array}$ & $\begin{array}{r}.00 \\
0\end{array}$ \\
\hline Madrasah (X) & & & & & \\
\hline
\end{tabular}

a. Dependent Variable: Peningkatan Mutu Pembelajaran(Y)

Berdasarkan hasil diatas diperoleh nilai konstanta pada kolom B. sehingga dapat diperoleh persamaan regresi sebagai berikut:

$\mathrm{Y}=\mathrm{a}+\mathrm{b} \mathrm{X}$

$\mathrm{Y}=6,810+0,667$ atau Peningkatan mutu pembelajaran = 6,810+o,667 (Supervisi akademik kepala madrasah)

Untuk mengetahui apakah persamaan regresi diatas dapat digunakan untuk memprediksi atau meramalkan besarnya variabel kriterium $(\mathrm{Y})$ berdasarkan variabel predictor $(\mathrm{X})$ dilakukan pengujian hipotesis untuk mengetahui analisis regresi linier sederhana, dibawah ini merupakan hasil analisis regresi linier sederhana dengan bantuan SPSS 26.

Tabel 4. ANOVAa

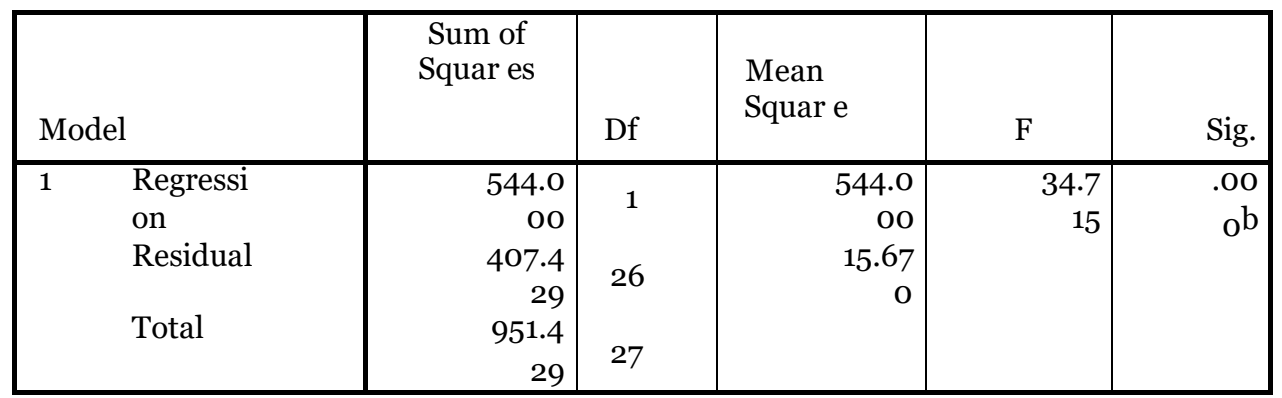

Dependent Variable: Peningkatan Mutu Pembelajaran(Y)

Predictors: (Constant), Supervisi Akademik Kepala Madrasah (X) 
Pada tabel ANOVA di atas diperoleh nilai Fhitung $=34.715$ akan dibandingan dengan Ftabel nilai Ftabel dengan dfreg $=\mathbf{1}$ dan dfres $=\mathbf{2 6}$ adalah 4,23 pada taraf $5 \%$ dan 7,72 pada taraf $1 \%$.

Dari hasil di atas didapat Ftabel pada df 1 dan dan 26 adalah 4,23 pada taraf $5 \%$ dan 7,72 pada taraf $1 \%$. Berdasarkan penjelasan diatas maka $34,715>4,23$ pada taraf $5 \%$ dan34,715>7,72 pada taraf $1 \%$. Sehingga Ho ditolak artinya Ada pengaruh yang signifikan antara supervisi akademik kepala madrasah dengan peningkatan mutu pembelajaran.

\section{PEMBAHASAN}

\section{Supervisi Akademik Kepala Madrasah (X)}

Pada dasarnya supervisi merupakan semua usaha yang dilakukan oleh seorang supervisor dalam bentuk pemberian bantuan, bimbingan, pengge-rakkan, motivasi, nasihat dan pengarahan yang bertujuan untuk meningkatkan hasil belajar siswa. Maka dari itu hasil analisis diatas, diperoleh bahwa para guru Madrasah Tsanawiyah Jamiatul Huda Kabupaten Bekasi mempersepsikan supervisi akademik yang dilaksanakan oleh kepala madrasah termasuk dalam kategori sangat tinggi dengan nilai sebesar 0.904 .

Hasil dari analisis penelitian bahwa perencanaan supervisi akademik yang dilakukan di MTs Jamiatul Huda Kabupaten Bekasi

yaitu dengan meren-canakan program tahunan dan semester sudah berjalan dengan baik. Pelaksanaan yang dilakukan dengan teknik dan prinsip yang mengacu kepada supervisi akademik telah digunakan. Kepala madrasah mengontrol langsung keadaan dilapangan dengan melakukan classroom observation (observasi kelas) yang tujuannya adalah untuk memperoleh data obyektif aspek- aspek situasi pembelajaran.

Berdasarkan hasil penelitian ini, maka kepala madrasah selaku supervisor harus membuat program supervisi akademik sesuai dengan kondisi masing- masing individu guru yang akan disupervisi, sehingga program tersebut bisa tepat, sesuai dengan situasi dan kondisi masingmasing individu guru. Dengan cara ini maka kepala madrasah selaku supervisor akan berhasil dalam menjalankan tugasnya.

Di samping sebagai supervisor kepala madrasah sebagai orang yang dijadikan panutan oleh orang-orang yang disupervisi, karena itu melalui pemberian contoh kegiatan belajar mengajar didepan kelas dan disiplin kerja yang tinggi dari kepala madrasah, guru dapat mencontoh dan mempraktikkan dalam melaksanakan tugas sehari-hari.

\section{Peningkatan Mutu Pembelajaran ( $Y$ )}

Peningkatan mutu pembelajaran tidak terlepas dari adanya supervisi akademik kepala madrasah. Tindak lanjut yang dilakukan oleh kepala madrasah terhadap kegiatan supervise akademik dilakukan dengan mengevaluasi dirapat rutinan. Evaluasi ini dilakukan sebagai 


\section{BESTARI}

Vol. 17, No. 2, 2020

p-ISSN 1907-1337; e-ISSN 2807-6532

bahan evaluasi atau forum untuk menjelaskan sisi mana yang harus diperbaiki proses pembelajarannya sehingga setiap guru akan memperbaiki cara mengajar mereka sesuai yang diharapkan.

Maka dari itu hasil analisis diatas, diperoleh bahwa untuk varibabel peningkatan mutu pembelajaran yang ada di MTs Jamiatul Huda Kabupaten Bekasi dengan kategori sangat tinggi, perolehan nilai distribusi sebesar 0.867 .

Dalam proses pembelajaran yang dilakukan, ada beberapa indicator untuk melihat kualitas pembelajaran meningkat di antaranya perilaku pembelajaran guru dengan membangun sikap positif siswa terhadap proses pembelajaran, iklim pembelajarann dengan membangun suasana yang kondusif bagi tumbuh dan berkembangnya kegiatan pembelajaran yang menarik, media pembelajaran dan instrument pembelajaran serta sisteem pembelajaran yang sesuai rencana strategis madrasah dan dirancang sesuai visi misi madrasah sehingga madrasah tsanawiyah Jamiatul Huda Kabupaten Bekasi dengan adanya kegiatan supervisi dalam proses pembelajarannya meningkat.

\section{Hubungan Supervisi Akademik Kepala Madrasah (X) Dengan} Peningkatan Mutu Pembelajaran ( $Y$ )

Adanya hubungan yang positif dan signifikan antara supervisi akademik kepala madrasah dengan peningkatan mutu pembelajaran di Madrasah Tsanawiyah Jamiatul Huda menunjukkan bahwa jika supervisi akademik kepala madrasah ditingkatkan, maka peningkatan mutu pembelajaran akan semakin meningkat. Hasil tersebut sangat logis, karena tujuan utama supervisi akademik kepala madrasah adalah untuk meningkatkan mutu pembelajaran, sehingga wajar kalau supervisi aakdemik kepala madrasah berdampak positif terhadap peningkatan mutu pembelajaran. Justru dampak positif inilah yang diharapkan.

Berdasarkan hasil analisis diperoleh persamaan regresi yaitu $\mathrm{Y}=$ $6,810+0,667 \mathrm{X}$. Berdasarkan pengujian hipotesis diperoleh nilai Fhitung $=34,715$ dan nilai Ftabel adalah 4,23, diambil keputusan bahwa Ho ditolak karena $F_{\text {hitung }}>F_{\text {tabel }}$ artinya ada hubungan yang signifikan antara Supervisi akademik kepala madrasah dengan peningkatan mutu pembelajaran. Jadi persamaan regresi tersebut dapat digunakan untuk meramalkan besarnya variabel kriterium (Y) berdasarkan variabel predictor (X).

Kemudian hasil dari uji signifikansi koefisien regresi variabel supervisi akademik kepala madrasah menunjukkan signifikan karena signifikan dari b adalah 0,000 , jauh lebih kecil dari taraf signifikan $5 \%$ atau 0,05 .

Penelitian ini mendukung penelitian-penelitian sebelumnya bahwa supervisi akademik kepala madrasah mempunyai hubungan yang positif dan signifikan dengan peningkatan mutu pembelajaran. Kepala madrasah selaku supervisor adalah seorang pemimpin bagi yang 
disupervisi. Kepala madrasah sebagai supervisor mempunyai tugas untuk membina para guru berkaitan dengan tugas pokoknya, yaitu membelajarkan siswa sehingga mencapai prestasi yang optimal.

Supervisor yang efektif adalah supervisor yang mampu menciptakan situasi yang kondusif, serta membimbing guru ke dalam suasana belajar mengajar yang efektif dan efisien. Berdasarkan hasil penleitian, hal ini telah dilakukan oleh para kepala madrasah sebagai supervisor.

Kepala madrasah telah menerapkan prinsip-prinsip supervisi yang efektif. Berdasarkan tabel 4.12 diperoleh nilai r2 determinasi sebesar 0,572, hal ini berarti 57,2\% variabel peningkatan mutu pembelajaran (Y) dipengaruhi oleh variabel supervisi akademik kepala madrasah (X) sedangkan sisanya 42,8\% dipengaruhi oleh variabel-variabel lainnya diluar penelitian ini.

Dengan kata lain variabelsupervisi akademik kepala madrasah sangat menentukan peningkatan mutu pembelajaran. Peningkatan mutu pembelajaran tidak lepas dari peran kepala madrasah dalam membina guru. Pembinaan terhadap guru bertujuan agar para guru dapat bekerja secara professional, sehingga kinerjanya akan semakin baik dan pada akhirnya dapat meningkatkan mutu pembelajaran dan mutu pendidikan.

Dari hasil penelitian menunjukkan bahwa dari persamaan regresi linier mempunyai hubungan yang positif dan signifikan dengan peningkatan mutu pembelajaran. Dengan demikian, semakin intensif supervisi akademik yang dilakukan oleh kepala madrasah dan semakin ditingkatkan sebagai supervisor maka akan semakin baik para kinerja guru berpengaruh pada peningkatan mutu pembelajaran,baik sendiri maupun secara bersama-sama

\section{SIMPULAN}

Berdasarkan hasil temuan-temuan dan pembahasan hasil penelitian, yang berjudul "Supervisi Akademik Kepala Madrasah Dengan Peningkatan Mutu Pembelajaran Di Madrasah Tsanawiyah Jamiatul Huda Kabupaten Bekasi”.

Berdasarkan hasil analisis dan pembahasan tentang korelasi dan regresi linier sederhana antara supervisi akademik kepala madrasah (X) dengan peningkatan mutu pembelajaran $(\mathrm{Y})$ dengan 28 responden di Madrasah Tsanawiyah Jamiatul Huda Kabupaten Bekasi, adapun kesimpulannya sebagai berikut: Supervisi akademik kepala madrasah di Madrasah Jamiatul Huda Kabupaten Bekasi. Para guru mempersepsikan supervisi akademik yang dilaksanakan oleh kepala madrasah termasuk dalam kategori sangat tinggi, dengan perolehan nilai distribusi sebesar o.904. Sebagaimana yang tertera dalam hasil analisis penelitian kepala madrasah menggunakan teknik dan prinsip dari supervisi akademik. Tindak lanjut yang dilakukan oleh kepala madrasah terhadap kegiatan supervisi akademik dilakukan secara bertahap melakukan evaluasi 


\section{BESTARI}

Vol. 17, No. 2, 2020

p-ISSN 1907-1337; e-ISSN 2807-6532

dengan waktu yang telah ditentukan. Semuanya dilakukan semata-mata hanya untuk meningkatkan mutu pembelajaran yang diharapkan oleh madrasah.

Peningkatan mutu pembelajaran tidak lepas dari peran kepala madrasah dalam membina guru. Pembinaan terhadap guru bertujuan agar para guru dapat bekerja secara professional, sehingga kinerjanya akan semakin baik. Dibuktikan dengan hasil analisis dengan variabel peningkatan mutu pembelajaran di MTs Jamiatul Huda Kabupaten Bekasi termasuk dalam kategori sangat tinggi. Dengan perolehan nilai sebesar 0,867

Hasil ini berdasarkan pada hasil analisis terkait indikator peningkatan mutu pembelajaran, untuk itu Kepala Madrasah tsanawiyah Jamiatul Huda Kabupaten Bekasi melakukan supervisi akademik bukan supervisi administasif saja. Supervisi akademik merupakan serangkaian kegiatan untuk membantu guru meningkatkan dan mengembangkan kemampuannya dalam melaksanakan proses belajar mengajar demi mencapai mutu pembelajaran.

Berdasarkan hasil penelitian dan pembahasan bahwa, besarnya antara supervisi akademik kepala madrasah (X) dengan peningkatan mutu pembelajaran $(\mathrm{Y})$ terdapat hubungan yang positif dan signifikan secara simultan yang ditunjukkan nilai Fhitung sebesar 34,715 dengan nilai sig. 0,000 dan dari koefisien determinasi r2 menyatakan bahwa sebesar 0,572. Atau 57,2\%. Koefisien determinasi menyatakan bahwa sebesar 57,2\% peningkatan mutu pembelajaran (Y) dipengaruhi oleh supervisi akademik kepala madrasah $(\mathrm{X})$ hal ini dengan garis regresi $\mathrm{Y}=6,810+0,667$.

Dari hasil penelitian menunjukkan bahwa dari persamaan regresi linier mempunyai hubungan yang positif dan signifikan dengan peningkatan mutu pembelajaran. Dengan demikian, semakin intensif supervisi akademik yang dilakukan oleh kepala madrasah dan semakin ditingkatkan sebagai supervisor maka akan semakin baik para kinerja guru berpengaruh pada peningkatan mutu pembelajaran,baik sendiri maupun secara bersama-sama.

\section{DAFTAR PUSTAKA}

Abdurrahman, M. (2012). Pendidikan Bagi Anak Berkesulitan Belajar. Jakarta: Reneka Cipta.

Eko Putro, Widoyoko(2012). Evaluasi Program Pembelajaran. Yogyakarta: Pustaka Pelajar.

Endang, Mulyatiningsih (2013). Metode Penelitian Terapan Bidang Pendidikan. Bandung: Alfabeta. 
Gunawan, A. H. (2011). Administrasi Sekolah. Jakarta: Rineka Cipta. Hasan, S. Hamid (2008). Evaluasi Kurikulum. Bandung: Remaja Rosda Karya.

Mintadji. (2015). Impelementasi Supervisi Akademik Kepala Sekolah SMP Negeri Di Tarakan. Jurnal Kebijakan dan Pengembangan Pendidikan, Vol.3, No.2, Januari.

Sukardi (2008). Evaluasi Pendidikan Prinsip \& Operasionalnya. Jakarta: Bumi Aksara, 2008.

Tayibnapis, Farida Yusuf (2008). Evaluasi Program dan Instrumen Evaluasi untuk Program Pendidikan dan Penelitian. Jakarta: Rineka Cipta. 2008.

Weiss, CH (1972). Evaluation Research. London: PrenticeHall. Inc Yusuf, Farida (2000) Evaluasi Program. Jakarta: Rineka Cipta. 